\title{
Prognostic Factors for Recovery of Vision in Canine Optic Neuritis of Unknown Etiology: 26 Dogs (2003-2018)
}

\author{
Christoforos Posporis ${ }^{1}$, Elsa Beltran ${ }^{2}$, Mark Dunning ${ }^{3,4}$, Irene Espadas ${ }^{1,5}$, \\ Sabrina Gillespie ${ }^{2}$, Amy Teresa Barry ${ }^{2}$ and Annette Wessmann ${ }^{1 *}$
}

${ }^{1}$ Neurology/Neurosurgery Service, Pride Veterinary Centre, Derby, United Kingdom, ${ }^{2}$ Queen Mother Hospital for Animals, Royal Veterinary College, Hatfield, United Kingdom, ${ }^{3}$ School of Veterinary Medicine and Science, University of Nottingham, Loughborough, United Kingdom, ${ }^{4}$ Willows Veterinary Centre and Referral Service, Shirley, United Kingdom, ${ }^{5}$ Small Animal Teaching Hospital, School of Veterinary Sciences, University of Liverpool, Neston, United Kingdom

\section{OPEN ACCESS}

Edited by: Andrea Tipold, University of Veterinary Medicine Hannover, Germany

Reviewed by:

Sarah A. Moore, The Ohio State University, United States Theresa Elizabeth Pancotto, Virginia Tech, United States

*Correspondence: Annette Wessmann Annette.Wessmann@ Scarsdalevets.com

Specialty section: This article was submitted to Veterinary Neurology and Neurosurgery,

a section of the journa Frontiers in Veterinary Science

Received: 22 September 2019 Accepted: 07 November 2019 Published: 22 November 2019

Citation: Posporis C, Beltran E, Dunning $M$, Espadas I, Gillespie S, Barry AT and Wessmann A (2019) Prognostic Factors for Recovery of Vision in Canine Optic Neuritis of Unknown Etiology: 26 Dogs (2003-2018). Front. Vet. Sci. 6:415 doi: 10.3389/fvets.2019.00415
Optic neuritis $(\mathrm{ON})$ is a recognized condition, yet factors influencing recovery of vision are currently unknown. The purpose of this study was to identify prognostic factors for recovery of vision in canine $\mathrm{ON}$ of unknown etiology. Clinical databases of three referral hospitals were searched for dogs with presumptive ON based on clinicopathologic, MRI/CT, and fundoscopic findings. Twenty-six dogs diagnosed with presumptive ON of unknown etiology, isolated (I-ON) and MUE-associated (MUE-ON), were included in the study. Their medical records were reviewed retrospectively, and the association of complete recovery of vision with signalment, clinicopathologic findings, and treatment was investigated. Datasets were tested for normality using the D'Agostino and Shapiro-Wilk tests. Individual datasets were compared using the Chi-squared test, Fisher's exact test, and the Mann-Whitney U-test. For multiple comparisons with parametric datasets, the one-way analysis of variance (ANOVA) was performed, and for non-parametric datasets, the Kruskal-Wallis test was performed to test for independence. For all data, averages are expressed as median with interquartile range and significance set at $p<0.05$. Twenty-six dogs met the inclusion criteria. Median follow-up was 230 days (range 21-1901 days, mean 496 days). Six dogs (23\%) achieved complete recovery and 20 dogs (77\%) incomplete or no recovery of vision. The presence of a reactive pupillary light reflex $(\rho=0.013)$, the absence of fundoscopic lesions $(p=0.0006)$, a younger age $(p=0.038)$, and a lower cerebrospinal fluid (CSF) total nucleated cell count (TNCC) $(p=0.022)$ were statistically associated with complete recovery of vision. Dogs with I-ON were significantly younger $(p=0.046)$ and had lower CSF TNCC $(p=0.030)$ compared to the MUE-ON group. This study identified prognostic factors that may influence complete recovery of vision in dogs with $\mathrm{ON}$. A larger cohort of dogs is required to determine whether these findings are robust and whether additional parameters aid accurate prognosis for recovery of vision in canine $\mathrm{ON}$.

Keywords: meningoencephalitis, immune-mediated, blindness, MUE, MUO, neuro-ophthalmology, optic nerve 


\section{INTRODUCTION}

Optic neuritis (ON) is a general term describing the pathological process of optic nerve inflammation and represents a clinical syndrome more than a specific disease $(1,2)$. Clinical signs are typically characterized by acute, bilateral or unilateral, partial or complete loss of vision $(1,3)$. Papillitis and neuroretinitis can be detected on fundoscopic examination (3-5) while retrobulbar ON generally lacks ophthalmoscopic abnormalities $(1,6,7)$. Classification focuses on the underlying etiology in veterinary medicine. Presumed immune-mediated (5-13), neoplastic $(1,5,14-19)$ and infectious diseases $(5,20-34)$ have been reported in association with ON. Other causes include extension of inflammation/infection and neoplasia from neighboring anatomical structures $(1,8,14,35)$, trauma (36), and toxins $(5,37,38)$.

Canine ON of unknown etiology is believed to be immunemediated. It is traditionally attributed to a focal form of granulomatous meningoencephalomyelitis (GME) or is considered part of a multifocal central nervous system (CNS) lesion-distribution of the same disease $(6,9,10,14,39-42)$. Optic neuritis has also been reported in a dog with necrotizing leukoencephalitis (NLE) (1,43). Both GME and NLE fall under the same umbrella term "meningoencephalomyelitis of unknown etiology (MUE)" but comprise disorders with clinicopathologic differences $(11,44-50)$. Definitive diagnosis requires histopathological examination (11, 44, 47, 51-53). In people, several pathogenetic theories have been proposed, and $\mathrm{ON}$ has been subdivided in typical and atypical forms (2). Optic neuritis is usually ascribed to multiple sclerosis (MS), and isolated forms are considered potential precursors of this disease (54). Other atypical causes of immune-mediated ON include neuromyelitis optica (NMO), neuromyelitis optica spectrum disorders (NMOSD), acute disseminated encephalomyelitis (ADEM), chronic recurrent immune optic neuropathy and autoimmune diseases with secondary optic nerve involvement $(2,55)$. These subtypes are characterized by distinct clinical courses and therapeutic requirements (2). Similarly, variations in the clinicopathologic presentation and outcome have been reported in dogs with idiopathic ON (5). There is currently no information available to classify canine $\mathrm{ON}$ cases as different phenotypic variants/stages of the same etiopathogenic entity or separate diseases.

\footnotetext{
Abbreviations: ON, optic neuritis; CNS, central nervous system; GME, granulomatous meningoencephalomyelitis; NLE, necrotizing leukoencephalitis; MUE, meningoencephalomyelitis of unknown etiology; PLR, pupillary light reflex; CSF, cerebrospinal fluid; TNCC, total nucleated cell count; CT, computed tomography; MRI, magnetic resonance imaging; ERG, electroretinography; FLAIR, fluid-attenuated inversion recovery; STIR, short tau inversion recovery; MUE-ON, MUE-associated ON; I-ON, isolated ON; mg, milligram; dl, deciliter; $\mu \mathrm{l}$, microliter; kg, kilogram; SID, semel in die (once daily); BID, bis in die (twice daily); NMO, neuromyelitis optica; NMOSD, neuromyelitis optica spectrum disorders; MS, multiple sclerosis; GFAP, glial fibrillary acidic protein; AQP-4, aquaporin 4; MOG, myelin oligodendrocyte glycoprotein; ADEM, acute disseminated encephalomyelitis; OPC, oligodendrocyte precursor cells; OCB, oligoclonal bands; TG-2, transglutaminase 2; MOGAD, MOG-IgGassociated disorder.
}

This study focuses on canine $\mathrm{ON}$ of presumed immunemediated etiology including isolated and MUE-associated forms. The clinicopathologic presentation, advanced imaging findings, treatment, and outcome in dogs with ON have been previously described $(1,3-12,16,39,40,56)$. While prognostic factors have been reported in dogs with MUE, such factors have not been specifically investigated with a focus on ON $(10,57-60)$. The purpose of this study is to identify prognostic factors for recovery of vision in canine $\mathrm{ON}$. The authors hypothesized that a shorter duration of blindness prior to immunosuppressive therapy and a lower cerebrospinal fluid (CSF) total nucleated cell count (TNCC) are associated with complete recovery of vision.

\section{MATERIALS AND METHODS}

This study followed a retrospective multi-center design. The clinical records of dogs diagnosed with $\mathrm{ON}$ were reviewed. The database of three referral veterinary hospitals was accessed from 2003 to 2018: Pride Veterinary Centre; Queen Mother Hospital for Animals, Royal Veterinary College; Small Animal Teaching Hospital, University of Liverpool. Ethical approval was granted at all institutions involved.

Dogs of any age, sex and breed were included if all of the following criteria were met: (a) physical and neurological assessment at presentation and follow-up examinations at least 21 days apart; (b) presence of visual disturbance assessed by a neurology and/or ophthalmology clinician (resident, residencytrained or board-certified) based on the ability to navigate successfully obstacles; (c) advanced imaging of the head (CT or MRI) classified as adequate in terms of sequence/plane selection and diagnostic quality and interpreted by a board-certified neurologist and radiologist; (d) fundoscopic and/or advanced diagnostic imaging findings consistent with ON; (e) a maximum of 3-week history of visual disturbance; (f) absent/incomplete menace response and/or absent/incomplete pupillary light reflex (PLR) in the affected eye/s that could not be explained by other clinicopathologic or imaging findings. Cases were excluded if one or more of the following criteria were met: (a) intracranial or extracranial neoplasia (suspected or confirmed); (b) ocular inflammation or infection; (c) presumed toxin exposure or adverse reactions to medications; (d) systemic or CNS infection suspected based on positive serological and/or CSF screening tests; (e) suspected or witnessed ocular and/or orbital trauma; (f) incomplete clinical records at presentation or follow-up examinations; (g) follow-up period $<21$ days.

Data retrieved from medical records included patient signalment (age, sex, breed, neuter status), clinical history, presenting complaint, clinical, neurological and ophthalmologic examination, therapeutic protocol, and outcome. Further diagnostic tests included $\mathrm{CBC}$, serum biochemistry profile, urinalysis, electroretinography (ERG), CSF analysis, and screening tests for infectious diseases. Protein concentration in CSF $>27 \mathrm{mg} / \mathrm{dl}$ for cerebellomedullary and TNCC $>5$ cells $/ \mu \mathrm{l}$ were classified as increased (61).

Fundoscopic findings were classified as consistent with ON when signs of papillitis and/or neuroretinitis were detected. 
Papillitis was characterized by a swollen optic disc with blurred margins, loss of the physiologic cup, raised blood vessels on the disc surface, hemorrhages and/or exudates involving the optic disc. Neuroretinitis was diagnosed when the extension of these pathological changes to the retina occurred $(1,3,4,7,12)$.

Magnetic resonance imaging of the head was performed using four 1.5 Tesla Magnets (Intera and Ingenia CX, Philips Medical Systems, Eindhoven, the Netherlands; Siemens Magnetom Essenza, Frimley, United Kingdom; HDe, GE Healthcare, United Kingdom). Selected sequences included T2-weighted, Fluid-Attenuated Inversion Recovery (FLAIR), Short Tau Inversion Recovery (STIR), Gradient Echo, preand post-contrast T1-weighted, and post-contrast T1-weighted fat suppression images. Sagittal, dorsal, transverse and oblique dorsal and sagittal planes were evaluated. CT of the head was performed using a 16-slice CT scanner (Mx8000 IDT, Philips, Best, the Netherlands). Post-contrast images were acquired using Gadoterate Meglumine (Dotarem ${ }^{\circledR}$, Guerbet, UK) for MRI and Iohexol (Omnipaque ${ }^{\circledR}$ 300, GE Healthcare, UK) for CT. Magnetic resonance imaging findings were assessed for optic nerve lesions consistent with $\mathrm{ON}$ as follows: presence of hyperintense signal on T2-weighted, FLAIR and STIR images; enhancement on T1-weighted post-contrast images and/or T1weighted fat suppression post-contrast images; enlargement of the optic nerve or optic chiasm with no significant mass lesion; loss of the subarachnoid CSF signal of the intra-orbital optic nerve segment secondary to thickening of the optic nerve; optic nerve head swelling $(7,12,13,62,63)$. Computed tomography findings of suspected $\mathrm{ON}$ consisted of the following abnormalities involving the optic nerve: contrast uptake; optic nerve head swelling; enlargement of the optic nerve or optic chiasm with no significant mass lesion (64-67).

Dogs were divided into two groups: presumptive MUEassociated $\mathrm{ON}$ with multifocal CNS disease (MUE-ON) and presumptive isolated ON (I-ON). Dogs with I-ON were characterized by the absence of clinical or advanced imaging findings involving the CNS outside the optic nerve. Dogs with MUE-ON had additional neurological deficits and/or advanced imaging findings involving the CNS outside the optic nerve. Group allocation did not depend on the results of CSF analysis.

Dogs receiving only corticosteroids were assigned in the monotherapy group and those treated with any additional immunosuppressive medication in the polytherapy group. The outcome was based on comparing the following parameters before and after treatment: the ability to navigate obstacles successfully, menace response, and PLR. The menace response was subjectively assessed as complete, incomplete, or absent. The PLR was classified as reactive (PLR present) referring to a complete or an incomplete reflex and non-reactive (PLR absent) referring to an absent reflex. Dogs were divided into two groups based on their visual outcome: (a) complete recovery of vision; (b) no or incomplete recovery of vision. Complete recovery of vision was characterized by the following: successful navigation of obstacles and normal vision reported by the owner; complete menace response in both eyes; complete PLR in both eyes. Incomplete recovery of vision was characterized by at least one of the following: partial improvement in navigating obstacles and partial improvement of vision reported by the owner; improved but incomplete menace response in at least one eye; improved but incomplete PLR in at least one eye. No recovery of vision was characterized by all of the following: no improvement of the ability to navigate obstacles and no improvement of vision reported by the owner; no improvement of the menace response with or without deterioration in either eye; no improvement of the PLR with or without deterioration in either eye. Dogs with no recovery of vision that further deteriorated as well as the prevalence of relapses in all dogs were recorded. Follow-up period was defined as the number of days from the first presentation until the final re-examination and communication with the owner and/or the referring veterinary surgeon. Follow-up data included clinical and neurological findings as well as telephone communications with owners and referring veterinary surgeons.

Statistical analysis was carried out using Graph Pad Prism 7.00 (GraphPad Software, La Jolla, California USA). Tests for normality were performed on each group (D'Agostino and Shapiro-Wilk Tests). Individual datasets were compared using the Chi-squared test, Fisher's exact test and the Mann- Whitney U-test. For multiple comparisons with parametric datasets, the one-way analysis of variance (ANOVA) was performed, and for non-parametric datasets, the Kruskal-Wallis test was performed to test for independence. Dunn's multiple comparisons test was used to analyze differences between specific groups. For all data, averages are expressed as median with interquartile range with significance set at $p<0.05$.

\section{RESULTS}

\section{Case Selection}

A total of 46 dogs with $\mathrm{ON}$ were identified. Nine cases were excluded due to insufficient follow-up (two dogs), inadequate clinical information (one dog), suspected infectious diseases (two dogs), suspected intracranial (three dogs), and extracranial (one dog) neoplasia. Eleven dogs did not meet the inclusion criteria due to the lack of advanced diagnostic imaging or negative MRI/CT and fundoscopy results. The remaining 26 dogs with ON fulfilled the inclusion criteria and were included in the study.

\section{Signalment}

The median age at presentation was 47.5 months (range 7132 months, mean 49.2 months). Males represented $58 \%$ of the population (15 dogs) and females $42 \%$ (11 dogs), with eight spayed female and 10 neutered male dogs. The most prevalent dog breed was French Bulldog with 11 cases (42\%), followed by Jack Russell Terrier with three cases, Shih Tzu and Lhasa Apso with two cases each and one dog from the following breeds: Patterdale Terrier, Bedlington Terrier, Finnish Lapphund, English Springer Spaniel, Border Collie, Boston Terrier, West Highland White Terrier, and Cairn Terrier. The prevalence of French Bulldogs in the general hospital canine population of two participating referral centers providing 22 out of 26 cases was $1.7 \%$. This information was not available from the third referral hospital. Median body weight at presentation was $10.8 \mathrm{~kg}$ (range $6-20.7 \mathrm{~kg}$, mean $11.6 \mathrm{~kg}$ ). Age at presentation had a significant 
TABLE 1 | Clinicopathologic findings with prognostic value in 26 dogs with ON.

\begin{tabular}{|c|c|c|c|c|c|c|c|c|}
\hline \multirow[t]{3}{*}{ Recovery of vision } & \multicolumn{8}{|c|}{ Statistically significant prognostic factors } \\
\hline & \multicolumn{3}{|c|}{ Age (months) } & \multirow[t]{2}{*}{ Dogs with reactive PLR (\%) } & \multirow[t]{2}{*}{ Dogs with fundoscopic lesions (\%)* } & \multicolumn{3}{|c|}{ CSF TNCC (cells/ $/ \mu \mathrm{l})$} \\
\hline & Median & Mean & Range & & & Median & Mean & Range \\
\hline Complete recovery & 21.5 & 26 & $7-62$ & $4 / 6(67 \%)$ & $1 / 5(20 \%)$ & 1.5 & 4.5 & $0-20$ \\
\hline Incomplete/no recovery & 58.5 & 56.2 & $11-132$ & $2 / 20(10 \%)$ & $18 / 18(100 \%)$ & 20 & 150 & $0-1,065$ \\
\hline$p$-value & & $0.038^{a}$ & & $0.013^{\mathrm{b}}$ & $0.0006^{b}$ & & $0.022^{a}$ & \\
\hline
\end{tabular}

PLR, pupillary light reflex; CSF, cerebrospinal fluid; TNCC, total nucleated cell count; $\mu l$, microliter.

*Fundoscopic examination was performed in 23 out of 26 dogs.

a Mann-Whitney test.

${ }^{b}$ Fisher's exact test.

effect on outcome $(p=0.038)$ (Table 1$)$. The younger the dog was at presentation, the more likely a complete recovery of vision. No statistically significant association was identified between complete recovery of vision and breed, gender, neuter status, or weight.

\section{Clinical Signs}

Ten dogs (38\%) had partial loss of vision while 16 (62\%) were completely blind at presentation. One dog had enucleation of one eye before ON; thus, a total of 51 eyes were assessed out of which 48 were classified as affected. A reactive PLR was observed in 19 out of 48 affected eyes (40\%; nine eyes with complete PLR, 10 eyes with incomplete PLR) while 29 eyes $(60 \%)$ were characterized by a non-reactive PLR. Menace response was abnormal in 45 out of 48 affected eyes (94\%) with an absent response in 43 and an incomplete response in two eyes. Except for two affected eyes in two different dogs, the menace response was always characterized by either the same or a worse degree of deficit compared to the PLR of the same eye at presentation. Visual deficits were predominantly bilateral (22 dogs; 85\%). The median duration of blindness before immunosuppressive treatment was 6 days (range 1-21 days, mean 7.3 days) and the median delay of treatment (time from presentation to immunosuppressive treatment) was 1 day (range $0-15$ days, mean 1.8 days). The presence of a reactive PLR ( $p=$ 0.013 ) at presentation was statistically associated with complete recovery of vision (Table 1). There was no statistically significant influence identified of the severity of menace response deficit, laterality of $\mathrm{ON}$, severity of visual disturbance and duration of blindness before immunosuppressive treatment.

\section{Investigations}

Infectious disease screening included CSF PCR for Toxoplasma gondii, Neospora caninum, Borrelia burgdorferi, Ehrlichia canis, Ehrlichia ewingii, Anaplasma phagocytophilum, Anaplasma platys, and Canine Distemper Virus; serum antibody titers for Toxoplasma gondii, Neospora caninum, Leptospira spp.; latex cryptococcal antigen test (LCAT) and in-clinic Idexx SNAP 4Dx Plus test (SNAP 4Dx Plus, IDEXX Laboratories, UK) for Ehrlichia canis, Ehrlichia ewingii, Borrelia burgdorferi, Anaplasma phagocytophilum and Anaplasma platys. All but five dogs were tested for infectious diseases and were negative.
Fundoscopic examination was performed in 23 cases (88\%), and lesions consistent with $\mathrm{ON}$ were found in 19 out of 23 $(83 \%)$. No abnormality was identified on fundoscopy in the remaining four dogs (17\%). Electroretinography was performed in nine cases, including the four dogs with normal fundoscopy and was within normal limits. The absence of fundoscopic lesions was significantly associated with complete recovery of vision $(p=0.0006)$ (Table 1$)$.

Advanced imaging of the head was performed in all cases (MRI in 25 dogs, CT scan in one dog). Lesions identified on advanced imaging were positive for ON in 21 dogs (81\%). All five dogs with no optic nerve lesions on MRI/CT were diagnosed with MUE, but concurrent ON was suspected clinically and was confirmed on fundoscopy. Thirteen out of 19 dogs (68\%) with MUE-ON showed no clinical signs referring to CNS disease outside the optic nerve on history or neurological examination. The absence of optic nerve lesions on MRI/CT was not associated with complete recovery of vision.

All dogs had cerebellomedullary CSF analysis performed. One case was excluded from further analysis of TNCC and protein concentration due to severe blood contamination. This case was classified as having normal CSF despite the iatrogenic blood contamination. For the remaining 25 cases, 17 (68\%) showed abnormalities. Fourteen dogs (56\%) had an increased protein concentration (median $30 \mathrm{mg} / \mathrm{dl}$, mean $56 \mathrm{mg} / \mathrm{dl}$, range 28490) and $13(52 \%)$ an elevated TNCC (median 20 cells/ $\mu 1$, mean 137 cells/ $\mu 1$, range $7-1,065)$. No statistically significant association was identified between CSF protein concentration and complete recovery. The CSF TNCC was significantly associated with complete recovery of vision $(p=0.022)$. The lower the TNCC the higher were the chances for complete recovery of vision (Table $\mathbf{1}$ ).

\section{Diagnosis}

Diagnosis of presumptive $\mathrm{ON}$ was reached based on the identification of both fundoscopic and advanced imaging findings consistent with $\mathrm{ON}$ in 14 dogs (54\%), advanced imaging findings alone in seven dogs (27\%) and fundoscopic findings alone in five dogs (19\%). The diagnosis was supported by the clinical/neurological examination findings, CSF analysis, ERG, and negative infectious diseases tests. Nineteen cases (73\%) were diagnosed with MUE-ON and seven (27\%) with I-ON. No 
TABLE 2 | Comparison of statistically significant clinicopathologic differences between dogs with MUE-ON and I-ON.

\begin{tabular}{|c|c|c|c|c|c|}
\hline \multirow[t]{3}{*}{ Type of ON } & \multicolumn{5}{|c|}{ Statistically significant clinicopathologic differences between groups } \\
\hline & \multirow[t]{2}{*}{ Median age (months) } & \multirow[t]{2}{*}{ Number of neutered dogs (\%) } & \multicolumn{3}{|c|}{ 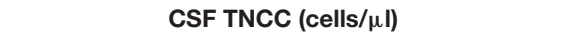 } \\
\hline & & & Median & Mean & Range \\
\hline MUE-ON & 59 & $16 / 19$ (84\%) & 20 & 128 & $0-1065$ \\
\hline $\mathrm{I}-\mathrm{ON}$ & 19 & $2 / 7(29 \%)$ & 2 & 82 & $0-560$ \\
\hline$p$-value & $0.046^{\mathrm{a}}$ & $0.014^{b}$ & & 0.030 & \\
\hline
\end{tabular}

MUE-ON, meningoencephalitis of unknown etiology-associated optic neuritis; I-ON, isolated optic neuritis; CSF, cerebrospinal fluid; TNCC, total nucleated cell count; $\mu$ l, microliter. a Mann-Whitney test.

${ }^{b}$ Fisher's exact test.

association was found between the diagnosis of I-ON or MUE$\mathrm{ON}$ and complete recovery of vision. Dogs with I-ON were significantly younger $(p=0.046)$ and had lower CSF TNCC $(p=0.030)$ compared to the MUE-ON group, which appeared to have significantly more neutered dogs $(p=0.014)$ (Table 2$)$. Dogs with fundoscopic lesions consistent with papillitis and/or neuroretinitis were statistically more likely to have a non-reactive PLR $(p=0.040)$, complete loss of vision $(p=0.024)$, higher CSF protein concentration $(p=0.029)$ and TNCC $(p=0.033)$ compared to dogs with retrobulbar $\mathrm{ON}$.

\section{Treatment}

Twelve dogs had received treatment before referral, but none was immunosuppressed. No history of any medications given prior to referral was available in two cases. Eyedrops (Maxitrol, Pred Forte, Azopt) were used in five dogs, non-steroidal antiinflammatories in six (meloxicam, carprofen, robenacoxib), a single anti-inflammatory dose of dexamethasone in one dog, antibiotics in three (amoxicillin-clavulanic acid, trimethoprim sulfadiazine), and chlorphenamine, paracetamol, tramadol, and imepitoin in one case each. The median duration of antiinflammatory therapy before presentation in these seven cases was 3 days (range $1-14$ days, mean $=5.4$ days). Their CSF TNCC at presentation was normal in two $(<5$ cells $/ \mu \mathrm{l})$ and increased in five dogs $($ median $=41$ cells $/ \mu \mathrm{l}$, mean $=116 \mathrm{cells} / \mu \mathrm{l}$, range seven to 404 cells/ $\mu \mathrm{l}$ ). After diagnosis, all dogs received immunosuppressive therapy on a tapering regimen consisting of at least corticosteroids (prednisolone or dexamethasone followed by prednisolone). One or more adjunctive immunosuppressive medications were used in 22 dogs $(85 \%)$ for at least one month: cytosine arabinoside (18 dogs), cyclosporine (four dogs), leflunomide (one dog), and lomustine (one dog). Antibiotics (clindamycin and doxycycline) were used briefly in three dogs and were discontinued once negative results from infectious diseases were received. No difference in outcome was identified between dogs treated with monotherapy or polytherapy.

\section{Follow-up, Outcome, and Relapses}

Follow-up ranged from 21 to 1,901 days (median 230; mean 496). Complete recovery of vision was achieved in six out of 26 dogs $(23 \%)$. Incomplete or no recovery of vision was recorded in 20 dogs $(77 \%)$ with $11(42 \%)$ showing signs of incomplete improvement and nine (35\%) having no recovery. Only one out of seven dogs pre-treated with anti-inflammatory medications prior to referral achieved complete recovery of vision. No deterioration after immunosuppressive treatment was seen in any of the cases. Seven out of nine dogs with no recovery of vision were diagnosed with MUE-ON. While their vision remained unchanged, improvement of their MUE-associated clinical signs was reported. Nine dogs (35\%) had at least one relapse from 102 to 827 days after the initial diagnosis of ON. Seven out of these nine dogs were diagnosed with MUE-ON and two with I-ON.

\section{DISCUSSION}

This study identified factors associated with visual recovery in 26 dogs with ON. A younger age, a reactive PLR, the absence of fundoscopic lesions, and a lower CSF TNCC at presentation were statistically associated with complete recovery of vision. To the best of our knowledge, no similar studies investigating prognostic factors in dogs with $\mathrm{ON}$ currently exist. In people with $\mathrm{ON}$, prognosis mainly depends on the underlying subtype of $\mathrm{ON}$, and diagnostic accuracy is highly relevant for approach to clinical management (68) (Table 3). Visual recovery is slightly worse in patients with MS-associated ON compared to those with isolated disease, but both have an overall positive long-term outcome (72). Atypical forms of ON such as NMO/NMOSD have a poorer prognosis and more recurrent attacks $(68,73-75)$. Severe loss of visual acuity at presentation $(76,77)$, specific ethnicity/race $(78)$, late treatment (79), bilateral ON (80), involvement of the intracanalicular part of the optic nerve on MRI, absence of retrobulbar pain (77), and older age at onset (76) were associated with poorer outcomes yet not all authors validated these results $(78,80)$.

The younger the dog was at presentation the higher were the chances for complete recovery of vision in this study population. Similarly, a recent publication investigating canine MUE showed that younger age at onset was associated with longer survival, but none of these dogs were diagnosed with concurrent $\mathrm{ON}$ (58). Still, other authors failed to repeat this finding $(11,57)$. In human medicine, pediatric $\mathrm{ON}$ is characterized by better recovery of visual acuity and lower annual relapse rates (76, $77,81-83)$. In contrast, younger-onset patients with NMO from the United Kingdom have a higher risk for visual disability (73). Interestingly, dogs with I-ON were significantly younger compared to those with MUE-ON. Considering the correlation between human medicine data and our results, a specific pediatric 
TABLE 3 | Severity and prognosis in human immune-mediated ON-associated diseases (68-71).

\begin{tabular}{|c|c|c|}
\hline $\begin{array}{l}\text { ON-associated } \\
\text { disease }\end{array}$ & Severity & Prognosis \\
\hline $\begin{array}{l}\text { MS-associated } \\
\text { ON } \\
\text { Solitary } \\
\text { (monophasic) } \\
\text { isolated ON }\end{array}$ & $\begin{array}{l}\text { Usually unilateral mild to } \\
\text { moderate visual loss and } \\
\text { mild periocular pain }\end{array}$ & $\begin{array}{l}\text { Spontaneous improvement in } \\
>90 \% \text { of patients }\end{array}$ \\
\hline $\begin{array}{l}\text { NMO-associated } \\
\text { ON }\end{array}$ & $\begin{array}{l}\text { Usually bilateral severe } \\
\text { visual loss } \\
\text { Transverse myelitis }\end{array}$ & $\begin{array}{l}\text { Incomplete recovery } \\
\text { Attacks of ON and/or } \\
\text { transverse myelitis recur in } \\
>85 \% \text { of patients with } \\
\text { paralysis or blindness seen in } \\
50 \% \text { of cases within } 5 \text { years }\end{array}$ \\
\hline $\begin{array}{l}\text { Chronic relapsing } \\
\text { inflammatory optic } \\
\text { neuropathy }\end{array}$ & $\begin{array}{l}\text { Usually bilateral severe } \\
\text { visual loss with persistence } \\
\text { of pain after onset of } \\
\text { blindness }\end{array}$ & $\begin{array}{l}\text { Steroid-responsive (long-term) } \\
\text { Frequent relapses when } \\
\text { treatment is } \\
\text { reduced/interrupted }\end{array}$ \\
\hline $\begin{array}{l}\text { ADEM-associated } \\
\text { ON }\end{array}$ & $\begin{array}{l}\text { High incidence in pediatric } \\
\text { population } \\
\text { Encephalomyelitis with } \\
\text { severe bilateral optic neuritis } \\
\text { in up to } 15 \% \text { of patients. }\end{array}$ & $\begin{array}{l}\text { Complete recovery in 56-94\% } \\
\text { Multiphasic ADEM in 0-23\% } \\
\text { Monophasic ADEM followed } \\
\text { by recurrent ON in 0-9\% } \\
\text { Residual visual deficits } \\
\text { are common }\end{array}$ \\
\hline
\end{tabular}

ON, optic neuritis; MS, multiple sclerosis; NMO, neuromyelitis optica; ADEM, acute disseminated encephalomyelitis.

ON phenotype could be considered in young dogs. The question also arises whether aging influences recovery and remyelination of the optic nerves or if benign phenotypes of $\mathrm{ON}$ are more common in younger dogs. Generally, remyelination decreases with age, as seen with any other regenerative process (84). Activation, recruitment, and differentiation of oligodendrocyte progenitor cells (OPC) decline with age (85-90). In addition, regulation of OPC behavior is influenced by signaling molecules secreted by macrophages or by phagocytized myelin debris containing inhibitors of OPC differentiation (91, 92). These processes are delayed with age $(89,93)$. Myelin debris clearance and remyelination are greater in younger animals due to more performant circulating monocytes (84). In clinical practice, the influence of aging could have an impact on demyelinating diseases such as $\mathrm{ON}$.

A high number of French Bulldogs (42\%) was recorded in our study. The popularity of the breed could have biased this finding but the prevalence of French Bulldogs in the general canine population of the referral hospitals providing 22 out of 26 cases was only $1.7 \%$. While MUE/ON represents $25 \%$ of encephalopathies in French Bulldogs (94), no data on familial inheritance is currently available in this breed. In people, genetic factors play a role in the development of MS and NMO, both of which are associated with ON but have significantly different prognosis (95-97). Interestingly, the strongest genetic risk in MS is related to the human leukocyte antigen (HLA) class II-DRB1 region which reflects similarities with the canine NME model association to the dog leucocyte antigen class II (DLA II) (98-101). Another common functional genetic variant between dogs and people was found outside the
HLA II region, within the IL7R gene $(96,101)$. Most of the French Bulldogs included in our study (73\%) were diagnosed with presumptive MUE, but the lack of histopathological confirmation prevented further categorization into NME or other types of MUE. The identification of predisposing genetic factors could achieve a more specific classification of canine ON sub-types. However, it is currently unclear if this could also result in prognostic contributions. Comprehending the differences in outcome and clinical course between distinct human $\mathrm{ON}$-associated disorders, one can also suspect the clinical relevance of a potential sub-categorization of canine $\mathrm{ON}$ in achieving accurate prognostication. The association between genetic predisposition and prognosis remains to be explored in future studies.

The impression that $\mathrm{ON}$ requires immediate immunosuppressive treatment predominates among practitioners. Surprisingly, the duration of blindness prior to immunosuppressive therapy was not statistically associated with the visual outcome in our study population; thus, one of our hypotheses was rejected. This finding can have clinical relevance in the decision-making process for the treatment of canine ON. One of the most common dilemmas clinicians face during this process is whether to start treatment immediately or to wait for results of infectious disease testing. Indeed, knowing if delaying treatment influences the prognosis or not can have an impact on clinical decision-making. In our study population, the six dogs with complete recovery of vision received treatment 2 days ( 1 case), 7 days ( 2 cases), 12 days ( 1 case), 13 days ( 1 case), and 21 days $(1 \mathrm{dog})$ after onset of blindness but still achieved complete recovery of vision. The possibility that treatment prior to presentation could have influenced the outcome by improving the chances of recovery was considered. However, only one out of seven dogs that were pre-treated with anti-inflammatory medications before referral achieved complete recovery of vision. Moreover, our data of seven pre-treated dogs showed elevation of CSF TNCC in five dogs, and thus it could not be concluded that pre-treatment prior to presentation has a protective effect or influence on the final outcome. Immunosuppressive medications were not used in any of the included cases prior to diagnosis of ON. Although our results suggest that duration of blindness prior to treatment does not appear to influence outcome, these findings require validation by larger sample size studies and changes in current practice cannot be recommended at this stage. Furthermore, the maximum duration of blindness prior to immunosuppressive treatment was 3 weeks, and this limited our ability to investigate the prognosis in dogs with longer treatment delay. Contrariwise, considering that factors such as presence of PLR, normal fundoscopy, and lower CSF TNCC were associated with complete recovery of vision, it is possible that parameters related to the severity of the disease have more prognostic value than its actual duration. In people with $\mathrm{ON}$, one study reported improved visual acuity in Thai patients with isolated $\mathrm{ON}$ treated within 8 days from onset (79). In another study, early treatment (within 7 days from onset) was associated with better short-term visual outcomes in people with severe acute $\mathrm{ON}$, but long-term visual acuity was not influenced by the timing of treatment (102). 
TABLE 4 | Biomarkers with prognostic value in people with ON (72, 81, 112, 118-139).

\begin{tabular}{|c|c|c|}
\hline Biomarker & Contribution in diagnosis & Prognostic value \\
\hline$A Q P-4 \mathrm{Ab}$ & $\begin{array}{l}\text { Positive in NMO } \\
\text { Negative in MS } \\
\text { Distinction of NMO from MS with } \\
\text { a sensitivity of } 68-91 \% \text { and } \\
\text { specificity of } 85-99 \%\end{array}$ & $\begin{array}{l}\text { More severe and relapsing ON } \\
\text { Higher rate of conversion to } \\
\text { NMO within } 1 \text { year } \\
\text { Poorer visual outcomes } \\
\text { compared to other phenotypes }\end{array}$ \\
\hline$O C B$ & $\begin{array}{l}\text { Positive in } 20-30 \% \text { of patients } \\
\text { with } \mathrm{NMO}, 6-13 \% \text { in MOGAD } \\
\text { and } 80 \% \text { in } \mathrm{MS} \text {. }\end{array}$ & $\begin{array}{l}\text { Spontaneous recovery in MS-ON } \\
\text { Lipid-specific oligoclonal IgM } \\
\text { bands could indicate a more } \\
\text { severe clinical course and predict } \\
\text { earlier onset of MS }\end{array}$ \\
\hline MOG $A b$ & $\begin{array}{l}\text { Diagnosis of MOGAD } \\
\text { Rare in adults with MS } \\
\text { Absent in AQP-4-seropositive } \\
\text { NMO patients } \\
\text { Seropositivity in children with } \\
\text { AQP-4-seronegative NMOSD, } \\
\text { recurrent ON, transverse myelitis } \\
\text { and multiphasic or } \\
\text { monophasic ADEM }\end{array}$ & $\begin{array}{l}\text { Similar to NMO phenotype but } \\
\text { better visual outcomes reported } \\
\text { Negative and positive clinical } \\
\text { courses reported } \\
\text { Recurrent attacks of ON }\end{array}$ \\
\hline Gly-R Ab & $\begin{array}{l}\text { Currently unknown } \\
\text { Positive in adults with ON }\end{array}$ & Relapsing isolated ON \\
\hline $\begin{array}{l}\text { NMDA-R } \\
A b\end{array}$ & $\begin{array}{l}\text { NMDA-R encephalitis } \\
\text { Positive in some adults with ON }\end{array}$ & $\begin{array}{l}\text { Monophasic episodes of } \\
\text { NMOSD, brainstem or multifocal } \\
\text { demyelinating syndromes }\end{array}$ \\
\hline GFAP & $\begin{array}{l}\text { Astrocytic biomarker of highly } \\
\text { active inflammation in NMO } \\
\text { GFAP concentration is believed } \\
\text { to be higher in NMO than in MS }\end{array}$ & $\begin{array}{l}\text { Correlation with clinical severity } \\
\text { was demonstrated between CSF } \\
\text { GFAP and NMO relapses but } \\
\text { also between serum GFAP and } \\
\text { relapsing-remitting MS }\end{array}$ \\
\hline $\begin{array}{l}\text { Interleukin- } \\
6 \\
\text { Interleykin- } \\
\text { 6-receptor }\end{array}$ & $\begin{array}{l}\text { Notable increases in CSF } \\
\text { interleukin- } 6 \text { and soluble } \\
\text { interleukin- } 6 \text { receptor } \\
\text { concentration identified in NMO }\end{array}$ & Currently unknown \\
\hline $\begin{array}{l}M R Z \\
\text { reaction }\end{array}$ & $\begin{array}{l}\text { Positive in MS (78\%) } \\
\text { Rare in most patients with } \\
\text { atypical types of ON such as } \\
\mathrm{NMO}, \mathrm{ADEM} \text { and } \\
\text { autoimmune encephalitis }\end{array}$ & Spontaneous recovery in MS-ON \\
\hline
\end{tabular}

AQP-4, aquaporin 4; MOG, myelin oligodendrocyte glycoprotein; MOGAD, MOG-lgGassociated disorder; Ab, antibody; Gly-R, glycine receptor a1 subunit; NMDA-R, Nmethyl-D-aspartate receptor; OCB, oligoclonal bands; NMOSD, neuromyelitis optica spectrum disorders; NMO, neuromyelitis optica; MS, multiple sclerosis; ADEM, acute disseminated encephalomyelitis; ON, optic neuritis; GFAP, glial fibrillary acidic protein; MRZ, measles, rubella and varicella zoster virus.

The presence of PLR was associated with complete recovery of vision in this study. The PLR can be a marker of optic nerve dysfunction (103). In people, quantitative PLR assessments show significantly decreased results in acute ON (104) and correlate with the severity of damage $(105,106)$. However, qualitative PLR examination is a subjective evaluation of the degree of pupillary constriction, which depends on the experience of the examiner and light intensity $(107,108)$. Our results showed that the presence of PLR is not uncommon among dogs with ON with $40 \%$ of affected eyes having a reactive PLR. Similarly, reactive PLR (incomplete or intact) was previously reported in $21 \%$ of eyes with immune-mediated ON (5). Hence, the presence of
PLR should not drive clinicians away from the neuroanatomical diagnosis of optic neuropathy.

The absence of fundoscopic lesions was associated with complete recovery of vision. As long as other pathognomonic features of $\mathrm{ON}$ are present and primary retinal pathology is ruled out, the lack of fundoscopic abnormalities is indicative of retrobulbar ON $(1,7)$. Based on previous reports $(5,7)$ and in corroboration with our data, it appears that retrobulbar ON has a low prevalence in dogs. In people, retrobulbar ON occurs in two-thirds of patients with typical ON (109). In our study, dogs with papillitis/neuroretinitis were statistically more likely to have a non-reactive PLR, complete loss of vision, higher CSF protein concentration and TNCC. It is possible that the involvement of the optic disc/retina is associated with more severe or irreversible lesions compared to a retrobulbar localization. We could also speculate that retrobulbar $\mathrm{ON}$ represents a less aggressive $\mathrm{ON}$ phenotype characterized by better visual outcomes. However, the absence of fundoscopic lesions is not a specific feature of certain $\mathrm{ON}$ phenotypes in people $(75,110)$. In addition, optic disc swelling accompanied by mild initial visual acuity loss was associated with better short-term outcomes in people with bilateral acute $\mathrm{ON}$, and this somewhat contradicts our findings (80).

A lower CSF TNCC was associated with complete recovery of vision in our study. Five out of six dogs with complete recovery of vision had a normal CSF TNCC, and these findings support one of our hypotheses. Smith and colleagues reported abnormal CSF analysis in 41 and $91 \%$ of dogs with MRI/CT-confirmed I$\mathrm{ON}$ and MUE-ON, respectively. Similar to our findings (Table 2), this study reported that the CSF TNCC was significantly higher in dogs with MUE-ON (median = 146 cells/ $\mu \mathrm{l}$ ) than in those with I-ON (median = five cells/ $\mu$ l) (5). In canine MUE, a higher CSF TNCC was associated with shorter survival (58), whereas this finding was dismissed by an earlier study (11). In people, the presence of CSF pleocytosis is not a pathognomonic feature of specific ON subtypes, but a greater pleocytosis is expected with NMO than MS (111-113). The degree of pleocytosis could correspond to the severity of inflammation and subsequent damage which then could have an impact on visual outcome. However, the significance of pleocytosis in canine immunemediated CNS diseases, including ON, is currently unknown. Interestingly, dogs with steroid-responsive meningitis arteritis can present with prominent pleocytosis but prognosis for recovery remains excellent with appropriate therapy (114-116), whereas up to $57 \%$ of dogs with MUE can have normal CSF cytology $(48,117)$ and this does not necessarily reflect a better prognosis $(11,57,60)$.

In search of prognostic factors in human $\mathrm{ON}$, the value of serum/CSF biomarkers in the classification of this syndrome in pathogenetically distinct phenotypes cannot be underestimated. Accurate diagnosis and differentiation between $\mathrm{ON}$ sub-types have been facilitated by the discovery of such markers (118122) (Table 4). This is closely related to prognosis due to their well-known differences in outcome, clinical course, and response to various therapies $(2,68-71,140,141)$. Even within the same ON phenotype, specific biomarkers have been demonstrated to predict the clinical course of the disease. For example, oligoclonal 
immunoglobulin $\mathrm{G}$ and $\mathrm{M}$ bands were shown to predict the onset of conversion of isolated ON to MS (123). In veterinary medicine, disease-specific markers and their potential prognostic value have not yet been validated. Auto-antibodies against astrocytes such as anti-glial fibrillary acidic protein (GFAP) $(142,143)$ and antitransglutaminase-2 (TG-2) antibodies (144) have been identified in dogs with MUE and particularly NME. Nonetheless, there is currently no evidence available linking the presence of these biomarkers to canine $\mathrm{ON}$ and its outcome.

The presence of optic nerve lesions on MRI/CT was not associated with the outcome in this study. While MRI appeared to have high sensitivity in identifying lesions suggestive of ON, $19 \%$ of included dogs had no MRI lesions of the optic nerve. This has been previously described in dogs with ON (5), and a normal MRI was also reported in $24 \%$ of dogs with inflammatory CSF (145). The overall agreement between neurological examination and MRI findings can be as low as $60 \%(48,146)$. Likewise, subclinical brain lesions were identified in $68 \%$ of our patients with MUE-ON. This demonstrates the limited sensitivity of the clinical assessment in identifying mild encephalopathic signs in visually impaired dogs $(48,146)$. It further highlights the importance of MRI in the diagnosis of $\mathrm{ON}$-associated diseases as the presence of parenchymal brain lesions may have an impact on the general prognosis and survival. Moreover, MRI is superior compared to CT in detecting such lesions. Thus it cannot be excluded that the one dog with CT-confirmed I-ON could have been misclassified as brain parenchymal lesions might have been missed.

Dogs with ON are traditionally treated with long-term immunosuppressive protocols. This is not a surprise considering the potential life-threatening implications of MUE and its frequent association with ON. In human patients, therapeutic requirements vary depending on the underlying etiology. In MS-associated ON, faster recovery can be seen with corticosteroids, but the long-term outcome is positive even without immunosuppressive therapy $(76,147)$. Chronic relapsing inflammatory optic neuropathy and NMO require high-dose and prolonged corticosteroid treatment (2). The investigation of canine ON phenotypes not requiring immunosuppression is highly problematic due to ethical considerations of not treating a condition that is frequently associated with MUE.

Visual outcome was generally poor in this study as only $23 \%$ of included dogs achieved significant visual recovery. Similar results were reported by Smith and colleagues, with only 17\% of dogs with ON achieving complete recovery of vision (5). Recurrence was recorded in $35 \%$ of our cases and is a known phenomenon in canine MUE and ON $(5,9,12,39)$. In people, recurrence occurs in $28 \%$ of patients within 5 years and $35 \%$ within 10 years $(148,149)$. The concurrent diagnosis of underlying diseases such as NMO and MS, the presence of unilateral ON and the use of relatively low initial glucocorticoid dosage were associated with higher recurrence rates (150). In our study, the concurrent diagnosis of MUE and the laterality of ON did not have an impact on visual outcomes. The association of different parameters with relapsing disease was not statistically investigated.

Limitations of this study are its retrospective multicenter nature and small sample size, especially of the complete recovery group. Fundoscopic examination was not performed in all dogs and this inevitably decreased the total number of cases used for statistical evaluation of fundoscopy as a prognostic factor. All 4 cases with normal fundoscopic examination achieved full recovery of vision and this was statistically significant in our population. Nevertheless, the limited sample size of dogs with fundoscopic examination remains a limitation. Additionally, the involvement of multiple clinicians inevitably results in some degree of subjective outcome assessment. This is probably most prominent in the assessment of vision and degree of PLR deficit. In an attempt to decrease the degree of subjective PLR assessment, the result of this test was classified as reactive or non-reactive in our study. Accurate evaluation of vision in dogs is challenging. Future studies should combine behavioral assessment of visual acuity (151) and clinical testing with more objective methods such as visual evoked potentials (VEP). This is performed in people with $\mathrm{ON}$ to assess conduction recovery along the visual pathway and represents a valuable tool in interpreting relapses (152). The use of VEP in dogs has been reported, and results are reliable and reproducible (153-155). Other diagnostic modalities are also gaining interest in clinical and research settings in human medicine. Optical coherence tomography is a high-resolution imaging technology with applications in monitoring the course of MS and the severity of optic nerve damage $(156,157)$. This technique has been described in veterinary literature (158), but its clinical application in canine $\mathrm{ON}$ is still premature.

A high degree of confidence for the diagnosis of ON was reached in most of our cases. Nonetheless, considering the lack of histopathological confirmation of MUE, other differentials cannot be entirely ruled out, and this represents another limitation. The overlap between the clinical profiles of ON and ischemic optic neuropathy in human patients (159) could also occur in dogs, and this disorder should be considered as a differential in canine patients with sudden-onset blindness. Ischemic optic neuropathy was reported in a dog with acute onset pre-chiasmatic blindness and was diagnosed on MRI with diffusion-weighted (DWI) and apparent diffusion coefficient (ADC) map sequences. Additional findings of a mesencephalic infarct and hypertension were detected and supported the diagnosis (160). Diffusion-weighted and ADC map sequences were not performed in our study, which could represent a limitation. However, MRI and/or fundoscopic features of ON together with other clinicopathologic findings supported the diagnosis in our patients. Moreover, the presence of optic nerve abnormalities on routine MRI sequences is significantly associated with the diagnosis of ON rather than ischemic optic neuropathy in people $(161,162)$.

Therapeutic protocols varied between the studied dogs, and this is another limitation as it might have influenced the outcome. One could further argue that infectious diseases could have been missed as not all pathogens previously linked to ON were investigated. However, none of the included dogs deteriorated after immunosuppressive treatment. Infectious diseases are generally uncommon in our geographic region, and studies failed to identify infectious agents in CSF and brain samples of dogs with MUE (163-166). In contrast, sporadic evidence of 
specific pathogens has been reported in dogs with MUE, but their implication in the development of the disease warrants further investigation (165, 167-169).

In conclusion, our study identified prognostic factors that were associated with complete recovery of vision in 26 dogs with ON. A larger cohort of dogs is required to determine whether our findings are robust and whether any additional measurable parameters aid accurate prognostication. The validation of prognostic factors in canine $\mathrm{ON}$ could assist clinicians in improving current clinical practice. Finally, the apparent clinicopathologic and prognostic variability between different $\mathrm{ON}$-associated diseases in people exposes the importance of developing an accurate etiopathogenic classification of distinct ON subtypes in dogs.

\section{DATA AVAILABILITY STATEMENT}

All datasets generated for this study are included in the article/supplementary material.

\section{ETHICS STATEMENT}

The animal study was reviewed and approved by all institutions (Pride Veterinary Centre/University of Nottingham: 2274

\section{REFERENCES}

1. Brooks DE, Martins BC. Diseases of the canine optic nerve. In: Gelatt KN, Gilger BC, Kern TJ, editors. Veterinary Ophthalmology. 5th ed. Ames, IA: Wiley-Blackwell (2013). p. 1460-1463.

2. Wilhelm H, Schabetm M. The diagnosis and treatment of optic neuritis. Deutsches Arzteblatt Int. (2015) 112:616-26. doi: 10.3238/arztebl.2015.0616

3. Nell B. Optic neuritis in dogs and cats. Vet Clin North Am Small Anim Pract. (2008) 38:403-15. doi: 10.1016/j.cvsm.2007.11.005

4. Nafe L, Carter J. Canine optic neuritis. Compendium Continuing Educ. (1981) 3:978-81.

5. Smith SM, Westermeyer HD, Mariani CL, Gilger BC, Davidson MG. Optic neuritis in dogs: 96 cases (1983-2016). Vet Ophthalmol. (2018) 21:442-51. doi: $10.1111 /$ vop. 12528

6. Adamo PF, Rylander H, Adams WM. Ciclosporin use in multi-drug therapy for meningoencephalomyelitis of unknown aetiology in dogs. J Small Anim Pract. (2007) 48:486-96. doi: 10.1111/j.1748-5827.2006.00303.x

7. Armour M, Broome M, Dell'Anna G, Blades NJ, Esson DW. A review of orbital and intracranial magnetic resonance imaging in 79 canine and 13 feline patients (2004-2010). Vet Ophthalmol. (2011) 14:215-26. doi: 10.1111/j.1463-5224.2010.00865.x

8. Smith-Maxie L, Cuddon PA. Reticulosis of the central nervous system in the dog. Compendium Contin. Educ. (1984) 6:23-32.

9. Fischer C. Neuro-ophthalmologic manifestations of primary reticulosis of the central nervous system in a dog. J Am Vet Med Assoc. (1971) 1:1240-8.

10. Munana KR, Luttgen PJ. Prognostic factors for dogs with granulomatous meningoencephalomyelitis: 42 cases (1982-1996). J Am Vet Med Assoc. (1998) 212:1902-6.

11. Coates J, Barone G, Dewey C, Vitale CL, Holloway-Azene NM, Sessions JK. Procarbazine as adjunctive therapy for treatment of dogs with presumptive antemortem diagnosis of granulomatous meningoencephalomyelitis: 21 cases (1998-2004). J Inter Vet Med. (2007) 21:100-6. doi: 10.1111/j.1939-1676.2007.tb02934.x

12. Seruca C, Rodenas S, Leiva M, Pena T, Anor S. Acute postretinal blindness: ophthalmologic, neurologic, and magnetic resonance imaging
180420; University of Liverpool: VREC664; Royal Veterinary College: URN SR2017-1191). Written informed consent was obtained from the owners for the participation of their animals in this study.

\section{AUTHOR CONTRIBUTIONS}

$\mathrm{CP}$ and $\mathrm{AW}$ designed and coordinated the study with the support of $\mathrm{EB}, \mathrm{MD}$, and IE. CP, SG, EB, AB, and IE provided all the necessary information from the clinical databases of the three participating referral hospitals. CP accessed and centralized all the clinical information. MD performed all the statistical analysis. $\mathrm{CP}$ processed the results and wrote the manuscript under the supervision and coordination of AW. All authors read and approved the final manuscript.

\section{ACKNOWLEDGMENTS}

This study was not supported by a grant. Preliminary results of this study have been submitted and presented at the 31st annual ESVN-ECVN symposium, September 20-22, 2018, Copenhagen, Denmark.

findings in dogs and cats (seven cases). Vet Ophthalmol. (2010) 13:307-14 doi: 10.1111/j.1463-5224.2010.00814.x

13. Kitagawa M, Okada M, Watari T, Sato T, Kanayama K, Sakai T. Ocular granulomatous meningoencephalomyelitis in a dog: magnetic resonance images and clinical findings. J Vet Med Sci. (2009) 71:233-7. doi: 10.1292/jvms.71.233

14. Suzuki M, Uchida K, Morozumi M. A comparative pathological study on granulomatous meningoencephalomyelitis and central malignant histiocytosis in dogs. J Vet Med Sci. (2003) 65:1319-24. doi: 10.1292/jvms.65.1319

15. Pumphrey SA, Pizzirani S, Pirie CG, Sato AF, Buckley FI. Reactive histiocytosis of the orbit and posterior segment in a dog. Vet Ophthalmol. (2013) 16:229-33. doi: 10.1111/j.1463-5224.2012.01055.x

16. Fischer C, Jones G. Optic neuritis in dogs. J Am Vet Med Assoc. (1972) 160:68-79.

17. Mauldin E, Deehr A, Hertzke D, Dubielzig RR. Canine orbital meningiomas: a review of 22 cases. Vet Ophthalmol. (2000) 3:11-6. doi: 10.1111/j.1463-5224.2000.00087.x

18. Naranjo C, Schobert C, Dubielzig R. Canine ocular gliomas: a retrospective study. Vet Ophthalmol. (2008) 11:356-62. doi: $10.1111 /$ j.1463-5224.2008.00658.x

19. Hendrix D, Gelatt K. Diagnosis, treatment and outcome of orbital neoplasia in dogs: a retrospective study of 44 cases. J Small Anim Pract. (2000) 41:105-8. doi: 10.1111/j.1748-5827.2000.tb03175.x

20. Cullen C, Webb A. Ocular manifestations of systemic disease. In: Gelatt KN, Gilger BC, Kern TJ, editors. Veterinary Ophthalmology. 5th ed. Ames, IA: Wiley-Blackwell (2013). p. 1897-1977.

21. Jergens A, Wheeler C, Collier L. Cryptococcosis involving the eye and central nervous system of a dog. J Am Vet Med Assoc. (1986) 189:302-4.

22. Bloom J, Hamor R, Gerding PJ. Ocular blastomycosis in dogs: 73 cases, 108 eyes (1985-1993). J Am Vet Med Assoc. (1996) 209:1271-1274.

23. Meadows R, MacWilliams P, Dzata G, Delauche AJ. Diagnosis of histoplasmosis in a dog by cytologic examination of CSF. Vet Clin Pathol. (1992) 21:122-4. doi: 10.1111/j.1939-165X.1992. tb00598.x 
24. Stadtbaumer K, Leschnik M, Nell B. Tick-borne encephalitis virus as a possible cause of optic neuritis in a dog. Vet Ophthalmol. (2004) 7:271-277. doi: 10.1111/j.1463-5224.2004.04030.x

25. Piper R, Cole C, Shadduck J. Natural and experimental ocular toxoplasmosis in animals. Am J Ophthalmol. (1970) 69:662-8. doi: 10.1016/0002-9394(70)91636-3

26. Leiva M, Naranjo C, Pena M. Ocular signs of canine monocytic ehrlichiosis: a retrospective study in dogs from Barcelona, Spain. Vet Ophthalmol. (2005) 8:387-93. doi: 10.1111/j.1463-5224.2005.00409.x

27. Schultze A, Ring R, Morgan R, Patton CS. Clinical, cytologic and histopathologic manifestations of protothecosis in two dogs. Vet Ophthalmol. (1998) 1:239-43. doi: 10.1046/j.1463-5224.1998.00034.x

28. Richards T, Whelan N, Pinard P, Alcala FC, Wolfe KC. Optic neuritis caused by canine distemper virus in a Jack Russell terrier. Can Vet J. (2011) 52:398-402.

29. Jubb K, Saunders L, Coates H. The intraocular lesions of canine distemper. J Comp Pathol. (1957) 67:21-9. doi: 10.1016/S0368-1742(57)80003-4

30. Adams J, Brown W, Snow H, Lincoln SD, Sears AW, Barenfus M, et al. Old dog encephalitis and demyelinating diseases in man. Vet Pathol. (1975) 12:220-6. doi: 10.1177/030098587501200307

31. Thomas W, Sorjonen D, Steiss J. A retrospective evaluation of 38 cases of canine distemper encephalomyelitis. I Am Anim Hosp Assoc. (1993) 29:129-33.

32. Baron M, Hecht S, Westermeyer H, Mankin JM, Novak JM, Donnell RL. Intracranial extension of retrobulbar blastomycosis (Blastomyces dermatitidis) in a dog. Vet Ophthalmol. (2011) 14:137-41. doi: $10.1111 /$ j.1463-5224.2010.00850.x

33. Monroe W. Clinical signs associated with pseudorabies in dogs. J Am Vet Med Assoc. (1989) 195:599-602.

34. Macintire D, Vincent-Johnson N, Dillon A, Blaqburn B, Lindsay D, Whitley EM, et al. Hepatozoonosis in dogs: 22 cases (1989-1994). J Am Vet Med Assoc. (1997) 210:916-22.

35. Wang A, Ledbetter E, Kern T. Orbital abscess bacterial isolates and in vitro antimicrobial susceptibility patterns in dogs and cats. Vet Ophthalmol. (2009) 12:91-6. doi: 10.1111/j.1463-5224.2008.00687.x

36. Gelatt K. Traumatic cataract and optic nerve atrophy in a dog. Vet Med Small Anim Clin. (1974) 69:988-9.

37. McEntee K, Grauwels M, Clercx C, Henroteaux M. Closantel intoxication in a dog. Vet Hum Toxicol. (1995) 37:234-6.

38. Helper LC. Diseases of vitreous, retina and optic nerve. In: Magrane WG, Helper LC, editors. Magrane's Canine Ophthalmology. 4th ed. Philadelphia: Lea \& Febiger (1989). p. 260.

39. Smith JS, DeLahunta A, Riis RC. Reticulosis of the visual system in a dog. J Small Anim Pract. (1977) 18:643-52. doi: 10.1111/j.1748-5827.1977.tb05832.x

40. Garmer N, Naeser P, Bergman A. Reticulosis of the eyes and the central nervous system in a dog. J Small Anim Pract. (1981) 22:39-45. doi: 10.1111/j.1748-5827.1981.tb01390.x

41. Zarfoss M, Schatzberg S, Venator K, Cutter-Schatzberg K, Cuddon P, Pintar J. Combined cytosine arabinoside and prednisone therapy for meningoencephalitis of unknown aetiology in 10 dogs. J Small Anim Pract. (2006) 47:588-95. doi: 10.1111/j.1748-5827.2006.00172.x

42. Summers B, Cummings J, DeLahunta A. Inflammatory diseases of the central nervous system. In: Summers B, Cummings J, deLahunta A, editors. Veterinary Neuropathology. St. Louis: Mosby (1995). p. 95-188.

43. Spitzbarth I, Schenk H, Tipold A, Beineke A. Immunohistochemical characterization of inflammatory and glial responses in a case of necrotizing leucoencephalitis in a French bulldog. J Comp Pathol. (2010) 142:235-41. doi: 10.1016/j.jcpa.2009.08.158

44. Stalis I, Chadwick B, Dayrell-Hart B, Summers BA, Van Winkle TJ. Necrotizing meningoencephalitis of maltese dogs. Vet Pathol. (1995) 32:2305. doi: 10.1177/030098589503200303

45. Sorjonen D. Clinical and histopathological features of granulomatous meningoencephalomyelitis in dogs. J Am Anim Hosp Assoc. (1990) 26:141-7.

46. Jung D, Kang B, Park C, Yoo JH, Gu SH, Jeon HW, et al. A comparison of combination therapy (cyclosporine plus prednisolone) with sole prednisolone therapy in 7 dogs with necrotizing meningoencephalitis. $J$ Vet Med Sci. (2007) 69:1303-6. doi: 10.1292/jvms.69.1303
47. Levine J, Fosgate G, Porter B, Schatzberg SJ, Greer K. Epidemiology of necrotizing meningoencephalitis in Pug dogs. J Vet Intern Med. (2008) 22:961-8. doi: 10.1111/j.1939-1676.2008.0137.x

48. Granger N, Smith P, Jeffery N. Clinical findings and treatment of non-infectious meningoencephalomyelitis in dogs: a systematic review of 457 published cases from 1962 to 2008. Vet J. (2010) 184:290-7. doi: 10.1016/j.tvjl.2009.03.031

49. Young B, Levine J, Fosgate G. Magnetic resonance imaging characteristics of necrotizing meningoencephalitis in Pug dogs. J Vet Inter Med. (2009) 23:527-35. doi: 10.1111/j.1939-1676.2009.0306.x

50. Flegel T. Breed-specific magnetic resonance imaging characteristics of necrotizing encephalitis in dogs. Front Vet Sci. (2017) 4:203. doi: 10.3389/fvets.2017.00203

51. Talarico L, Schatzberg S. Idiopathic granulomatous and necrotising inflammatory disorders of the canine central nervous system: a review and future perspectives. J Small Anim Pract. (2010) 51:138-49. doi: 10.1111/j.1748-5827.2009.00823.x

52. Higgins R, Dickinson P, Kube S, Moore PF, Couto SS, Vernau KM, et al. Necrotizing meningoencephalitis in five Chihuahua dogs. Vet Pathol. (2008) 45:336-46. doi: 10.1354/vp.45-3-336

53. Eberly J, Hague D, Singh K, Lezmi S. Pathology in practice. Necrotizing leukoencephalitis (NLE). J Am Vet Med Assoc. (2015) 247:361-3. doi: 10.2460/javma.247.4.361

54. Langer-Gould A, Brara S, Beaber B, Zhang JL. The incidence of clinically isolated syndrome in a multi-ethnic cohort. J Neurol. (2014) 261:1349-55. doi: 10.1007/s00415-014-7349-0

55. Huppke P, Rostasy K, Karenfort M, Huppke B, Seidl R, Leiz S, et al. Acute disseminated encephalomyelitis followed by recurrent or monophasic optic neuritis in pediatric patients. Mult Scler J. (2013) 19:941-6. doi: $10.1177 / 1352458512466317$

56. Vandevelde M, Kristensen B, Greene C. Primary reticulosis of the central nervous system in the dog. Vet Pathol. (1978) 15:673-5. doi: $10.1177 / 030098587801500512$

57. Cornelis I, Volk H, Van Ham L, De Decker S. Prognostic factors for 1-week survival in dogs diagnosed with meningoencephalitis of unknown aetiology. Vet J. (2016) 214:91-5. doi: 10.1016/j.tvjl.2016.05.008

58. Oliphant B, Barnes Heller HL, White JM. Retrospective study evaluating associations between midline brain shift on magnetic resonance imaging and survival in dogs diagnosed with meningoencephalitis of unknown etiology. Vet Radiol Ultrasound. (2017) 58:38-43. doi: 10.1111/vru.12434

59. Cornelis I, Volk H, De Decker S. Clinical presentation, diagnostic findings and long-term survival in large breed dogs with meningoencephalitis of unknown aetiology. Vet Rec. (2016) 179:147. doi: 10.1136/vr. 103640

60. Lowrie M, Smith P, Garosi L. Meningoencephalitis of unknown origin: investigation of prognostic factors and outcome using a standard treatment protocol. Vet Rec. (2013) 172:527. doi: 10.1136/vr.101431

61. Di Terlizzi R, Platt SR. The function, composition and analysis of cerebrospinal fluid in companion animals: Part I-Function and composition. Vet J. (2006) 172:422-31. doi: 10.1016/j.tvjl.2005.07.021

62. Gala F. Magnetic resonance imaging of optic nerve. Indian J Radiol Imaging. (2015) 25:421-38. doi: 10.4103/0971-3026.169462

63. Khanna S, Sharma A, Huecker J, Gordon M, Naismith RT, Van Stavern GP. Magnetic resonance imaging of optic neuritis in patients with neuromyelitis optica versus multiple sclerosis. J Neuro Ophthalmol. (2012) 32:216-20. doi: 10.1097/WNO.0b013e318254c62d

64. Wall M, Weisber L. CT findings in acute optic neuritis. Comput Radiol. (1984) 8:91-4. doi: 10.1016/0730-4862(84)90068-4

65. Booth F, Hallinan J. Optic neuritis and computed tomography. Aust J Ophthalmol. (1980) 8:307-9. doi: 10.1111/j.1442-9071.1980.tb00287.x

66. Unsöld R. On the CT-diagnosis of optic nerve lesions. Differential diagnostic criteria. Graefes Arch Clin Exp Ophthalmol. (1982) 218:124-38. doi: 10.1007/BF02215649

67. Peyster R, Hoover E, Hershey B, Haskin ME. High-resolution CT of lesions of the optic nerve. Am J Roentgenol. (1983) 140:869-74. doi: 10.2214/ajr.140.5.869

68. Toosy A, Mason D, Miller D. Optic neuritis. Lancet Neurol. (2014) 13:83-99. doi: 10.1016/S1474-4422(13)70259-X 
69. Hoorbakht H, Bagherkashi F. Optic neuritis, its differential diagnosis and management. Open Ophthalmol J. (2012) 6:65-72. doi: 10.2174/1874364101206010065

70. Kidd D, Burton B, Plant GT, Graham EM. Chronic relapsing inflammatory optic neuropathy (CRION). Brain. (2003) 126:276-84. doi: 10.1093/brain/awg045

71. Cole J, Evans E, Mwangi M, Mar S. Acute disseminated encephalomyelitis in children: an updated review based on current diagnostic criteria. Pediatr Neurol (2003) 100:26-34. doi: 10.1016/j.pediatrneurol.2019.06.017

72. Brodsky M, Orengo-Nania S, Hutton G, Slight B, Buckley EG, Massey EW, et al. Optic Neuritis Study Group. Visual function 15 years after optic neuritis: a final follow-up report from the optic neuritis treatment trial. Ophthalmology. (2008) 115:1079-82.e5. doi: 10.1016/j.ophtha.2007.08.004

73. Kitley J, Leite M, Nakashima I, Waters P, McNeillis B, Brown R, et al. Prognostic factors and disease course in aquaporin-4 antibodypositive patients with neuromyelitis optica spectrum disorder from the United Kingdom and Japan. Brain. (2012) 135:1834-49. doi: 10.1093/brain/aws109

74. Lin N, Liu Q, Wang X, Ma J, Li Y. Role of AQP4 antibody serostatus and its prediction of visual outcome in neuromyelitis optica: a systematic review and meta-analysis. Prot Pept Lett. (2017) 24:245-52. doi: 10.2174/0929866524666170110150436

75. Hansapinyo L, Vivattanaseth C. Clinical characteristics, treatment outcomes and predictive factors in optic neuritis. Open Ophthalmol J. (2018) 12:247-55. doi: 10.2174/1874364101812010247

76. Beck R, Cleary P, Backlund J. The course of visual recovery after optic neuritis. Experience of the optic neuritis treatment trial. Ophthalmology. (1994) 101:1771-8. doi: 10.1016/S0161-6420(94)31103-1

77. Deschamps R, Gout O, Fontaine B, Rigolet MH, Cabanis EA, Lyon-Caen O, et al. Acute optic neuritis: clinical and MRI prognostic factors. Study of fifty patients. Revue Neurol. (2002) 158:446-52.

78. Moss H, Gao W, Balcer L, Joslin CE. Association of race/ethnicity with visual outcomes following acute optic neuritis: an analysis of the optic neuritis treatment trial. JAMA Ophthalmol. (2014) 132:421-7. doi: 10.1001/jamaophthalmol.2013.7995

79. Chuenkongkaew W, Chirapapaisan N. Optic neuritis: characteristics and visual outcome. J Med Assoc Thai. (2003) 86:238-43.

80. Du Y, Li K, Yang J, Xu X, Li JJ, Zhou RW, et al. Disc swelling and mild initial visual acuity loss predict a better short-term visual acuity outcome in bilateral acute optic neuritis. J Clin Neurosci. (2012) 19:1380-2. doi: 10.1016/j.jocn.2011.10.020

81. Song H, Zhou H, Yang M, Xu Q, Sun M, Wei S. Clinical characteristics and outcomes of myelin oligodendrocyte glycoprotein antibody-seropositive optic neuritis in varying age groups: A cohort study in China. J Neurol Sci. (2019) 400:83-9. doi: 10.1016/j.jns.2019.03.014

82. Averseng-Peaureaux D, Mizzi M, Colineaux H, Mahieu L, Pera MC, Brassat D, et al. Paediatric optic neuritis: factors leading to unfavourable outcome and relapses. Br J Ophthalmol. (2018) 102:808-13. doi: 10.1136/bjophthalmol-2016-309978

83. Borchert M, Liu G, Pineles S, Waldman AT. Pediatric optic neuritis: what is new. J Neuro-Ophthalmol. (2017) 37(Suppl 1):S14-S22. doi: 10.1097/WNO.0000000000000551

84. Miron VE, Franklin RJ. Macrophages and CNS remyelination. J Neurochem. (2014) 130:165-71. doi: 10.1111/jnc.12705

85. Sim FJ, Zhao C, Penderis J, Franklin RJ. The age-related decrease in CNS remyelination efficiency is attributable to an impairment of both oligodendrocyte progenitor recruitment and differentiation. J Neurosci. (2002) 22:2451-9. doi: 10.1523/JNEUROSCI.22-07-024 51.2002

86. Fancy S, Zhao C, Franklin RJ. Increased expression of Nkx2.2 and Olig2 identifies reactive oligodendrocyte progenitor cells responding to demyelination in the adult CNS. Mol Cell Neurosci. (2004) 27:247-54. doi: 10.1016/j.mcn.2004.06.015

87. Woodruff R, Fruttiger M, Richardson W, Franklin RJ. Platelet-derived growth factor regulates oligodendrocyte progenitor numbers in adult CNS and their response following CNS demyelination. Mol Cell Neurosci. (2004) 25:252-62. doi: 10.1016/j.mcn.2003.10.014
88. Shen S, Sandoval J, Swiss V, Li J, Dupree J, Franklin RJ, et al. Age-dependent epigenetic control of differentiation inhibitors is critical for remyelination efficiency. Nat Neurosci. (2008) 11:1024-34, 2008. doi: 10.1038/nn.2172

89. Hinks G, Franklin RJ. Delayed changes in growth factor gene expression during slow remyelination in the CNS of aged rats. Mol Cell Neurosci. (2000) 16:542-56. doi: 10.1006/mcne.2000.0897

90. Zhao C, Li W, Franklin RJ. Differences in the early inflammatory responses to toxin-induced demyelination are associated with the agerelated decline in CNS remyelination. Neurobiol Aging. (2006) 27:1298-307. doi: 10.1016/j.neurobiolaging.2005.06.008

91. Kotter M, Li W, Zhao C. Myelin impairs CNS remyelination by inhibiting oligodendrocyte precursor cell differentiation. J Neurosci. (2006) 26:328-32. doi: 10.1523/JNEUROSCI.2615-05.2006

92. Baer A, Syed Y, Kang S, Mitteregger D, Vig R, Ffrench-Constant C, et al. Myelin-mediated inhibition of oligodendrocyte precursor differentiation can be overcome by pharmacological modulation of Fyn-RhoA and protein kinase C signalling. Brain. (2009) 132:465-81. doi: 10.1093/brain/awn334

93. Ruckh J, Zhao J, Shadrach J, Van Wijngaarden P, Rao TN, Wagers AJ, et al. Rejuvenation of regeneration in the aging central nervous system. Cell Stem Cell. (2012) 10:96-103. doi: 10.1016/j.stem.2011.11.019

94. Mayousse V, Desquilbet L, Jeandel A, Blot S. Prevalence of neurological disorders in French bulldog: a retrospective study of 343 cases (2002-2016). BMC Vet Res. (2017) 13:212. doi: 10.1186/s12917-017-1132-2

95. Ramagopalan S, Dobson R, Meier U. Multiple sclerosis: risk factors, prodromes, and potential causal pathways. Lancet Neurol. (2010) 9:727-39. doi: 10.1016/S1474-4422(10)70094-6

96. Lundmark F, Duvefelt K, Iacobaeus E, Kockum I, Wallstrom E, Khademi M, et al. Variation in interleukin 7 receptor alpha chain (IL7R) influences risk of multiple sclerosis. Nat Genet. (2007) 39:1108-13. doi: 10.1038/ng2106

97. Estrada K, Whelan C, Zhao F, Bronson P, Handsaker RE, Sun $\mathrm{C}$, et al. A whole-genome sequence study identifies genetic risk factors for neuromyelitis optica. Nat Commun. (2018) 9:1929. doi: 10.1038/s41467-018-04332-3

98. Hollenbach J, Oksenberg J. The immunogenetics of multiple sclerosis: a comprehensive review. J Autoimmun. (2015) 64:13-25. doi: 10.1016/j.jaut.2015.06.010

99. Barber R, Schatzberg S, Corneveaux J, Allen AN., Porter BF, Pruzin JJ, et al. Identification of risk loci for necrotizing meningoencephalitis in Pug dogs. J Heredity. (2011) 102(Suppl) :S40-6. doi: 10.1093/jhered/esr048

100. Greer K, Wong A, Liu H, Famula TR, Pedersen NC, Ruhe A, et al. Necrotizing meningoencephalitis of Pug dogs associates with dog leukocyte antigen class II and resembles acute variant forms of multiple sclerosis. Tissue Antigens. (2010) 76:110-8. doi: 10.1111/j.1399-0039.2010.01484.x

101. Schrauwen I, Barber R, Schatzberg S, Siniard AL, Corneveaux JJ, Porter BF, et al. Identification of novel genetic risk loci in Maltese dogs with necrotizing meningoencephalitis and evidence of a shared genetic risk across toy dog breeds. Tissue Antigens. (2014) 9:e112755. doi: 10.1371/journal.pone.0112755

102. Dale GH, Petersen T, Bacher Svendsen K, Christensen T, Houen G, Bek T. Time to steroid treatment in severe acute optic neuritis. Brain Behav. (2018) 8:e01032. doi: 10.1002/brb3.1032

103. Levatin P. Pupillary escape in disease of the retina or optic nerve. Archiv Ophthalmol. (1959) 62:768-79. doi: 10.1001/archopht.1959.04220050030005

104. Yoo Y, Hwang J, Yang H. Differences in pupillary light reflex between optic neuritis and ischemic optic neuropathy. PLoS ONE. (2017) 12:e0186741. doi: 10.1371/journal.pone.0186741

105. Thompson H, Montague P, Cox T, Corbett JJ. The relationship between visual acuity, pupillary defect, and visual field loss. Am J Ophthalmol. (1982) 93:681-8. doi: 10.1016/0002-9394(82)90460-3

106. Johnson L, Hill R, Bartholomew M. Correlation of afferent pupillary defect with visual field loss on automated perimetry. Ophthalmology. (1988) 95:1649-55. doi: 10.1016/S0161-6420(88)32962-3

107. Litvan I, Saposnik G, Maurino J. Pupillary diameter assessment: need for a graded scale. Neurology. (2000) 54:530-1. doi: 10.1212/WNL.54.2.530

108. Bergamin O, Kardon R. Latency of the pupil light reflex: sample rate, stimulus intensity, and variation in normal subjects. Investig Ophthalmol Visual Sci. (2003) 44:1546-54. doi: 10.1167/iovs.02-0468 
109. Optic Neuritis Study Group. The clinical profile of optic neuritis. Experience of the Optic Neuritis Treatment Trial. Archiv Ophthalmol. (1991) 109:16738. doi: 10.1001/archopht.1991.01080120057025

110. Srikajon J, Siritho S, Ngamsombat C, Prayoonwiwat N, Chirapapaisan $\mathrm{N}$, Siriraj Neuroimmunology Research Group. Differences in clinical features between optic neuritis in neuromyelitis optica spectrum disorders and in multiple sclerosis. Mult Scler J. (2018) 4:2055217318791196. doi: $10.1177 / 2055217318791196$

111. O'Riordan J, Gallagher H, Thompson A, Howard RS, Kingsley DP, Thompson EJ, et al. Clinical, CSF, and MRI findings in Devic's neuromyelitis optica. J Neurol Neurosurg Psychiatry. (1996) 60:382-7. doi: $10.1136 /$ jnnp.60.4.382

112. Jarius S, Paul F, Franciotta D, Ruprecht K, Ringelstein M, Bergamaschi $\mathrm{R}$, et al. Cerebrospinal fluid findings in aquaporin-4 antibody positive neuromyelitis optica: results from 211 lumbar punctures. J Neurol Sci. (2011) 306:82-90. doi: 10.1016/j.jns.2011.03.038

113. Wingerchuk D, Hogancamp W, O'Brien P, Weinshenker BG. The clinical course of neuromyelitis optica (Devic's syndrome). Neurology. (1999) 53:1107-14. doi: 10.1212/WNL.53.5.1107

114. Tipold A, Jaggy A. Steroid responsive meningitis-arteritis in dogs: Long-term study of 32 cases. J Small Anim Pract. (1994) 35:311-6. doi: 10.1111/j.1748-5827.1994.tb03293.x

115. Cizinauskas S, Jaggy A, Tipold A. Long-term treatment of dogs with steroid-responsive meningitis-arteritis: clinical, laboratory and therapeutic results. J Small Anim Pract. (2000) 41:295-301. doi: $10.1111 / j .1748-5827.2000 . t b 03205 . x$

116. Lowrie M, Penderis J, McLaughlin M, Eckersall PD, Anderson TJ. Steroid responsive meningitis-arteritis: a prospective study of potential disease markers, prednisolone treatment, and long-term outcome in 20 dogs (2006-2008). J Vet Intern Med. (2009) 23:862-70. doi: 10.1111/j.1939-1676.2009.0337.x

117. Menaut P, Landart J, Behr S. Treatment of 11 dogs with meningoencephalomyelitis of unknown origin with a combination of prednisolone and cytosine arabinoside. Vet Rec. (2008) 162:241-5. doi: 10.1136/vr.162.8.241

118. Lennon V, Wingerchuk D, Kryzer $T$, Pittock SJ, Lucchinetti CF, Fujihara K, et al. A serum autoantibody marker of neuromyelitis optica: distinction from multiple sclerosis. Lancet. (2004) 364:2106-012. doi: 10.1016/S0140-6736(04)17551-X

119. Weber M, Derfuss T, Metz I, Bruck W. Defining distinct features of anti-MOG antibody associated central nervous system demyelination. Ther Adv Neurol Disord. (2018) 11:1756286418762083. doi: $10.1177 / 1756286418762083$

120. Jarius S, Frederikson J, Waters P, Paul F, Akman-Demir G, Marignier $\mathrm{R}$, et al. Frequency and prognostic impact of antibodies to aquaporin4 in patients with optic neuritis. J Neurol Sci. (2010) 298:158-62. doi: 10.1016/j.jns.2010.07.011

121. Jarius S, Ruprecht K, Wildemann B, Kuempfel T, Ringelstein M, Geis C, et al. Contrasting disease patterns in seropositive and seronegative neuromyelitis optica: a multicentre study of 175 patients. J Neuroinflamm. (2012) 9:14. doi: 10.1186/1742-2094-9-14

122. Jarius S, Franciotta D, Bergamaschi R, Rauer S, Wandinger KP, Petereit HF, et al. Polyspecific, antiviral immune response distinguishes multiple sclerosis and neuromyelitis optica. J Neurol Neurosurg Psychiatry. (2008) 79:1134-6. doi: 10.1136/jnnp.2007.133330

123. Tejeda-Velarde A, Costa-Frossard L, Sainz de la Maza S, Carrasco A, Espino $\mathrm{M}$, Picon C, et al. Clinical usefulness of prognostic biomarkers in optic neuritis. Eur J Neurol. (2018) 25:614-8. doi: 10.1111/ene.13553

124. Papadopoulos M, Verkman A. Aquaporin 4 and neuromyelitis optica. Lancet Neurol. (2012) 11:535-44. doi: 10.1016/S1474-4422(12) 70133-3

125. Martinez-Hernandez E, Sepulveda M, Rostasy K, Hoftberger R, Graus F, Harvey RJ, et al. Antibodies to aquaporin 4, myelinoligodendrocyte glycoprotein, and the glycine receptor alphal subunit in patients with isolated optic neuritis. JAMA Neurol. (2015) 72:187-93. doi: 10.1001/jamaneurol.2014.3602

126. Alvarez-Cermeno J, Munoz-Negrete F, Costa-Frossard L, Sainz de la Maza S, Villar LM, Rebolleda G. Intrathecal lipid-specific oligoclonal IgM synthesis associates with retinal axonal loss in multiple sclerosis. J Neurol Sci. (2016) 360:41-4. doi: 10.1016/j.jns.2015.11.030

127. Ferraro D, Galli V, Vitetta F, Simone AM, Bedin R, Del Giovane C, et al. Cerebrospinal fluid CXCL13 in clinically isolated syndrome patients: association with oligoclonal $\mathrm{IgM}$ bands and prediction of multiple sclerosis diagnosis. J Neuroimmunol. (2015) 283:64-9. doi: 10.1016/j.jneuroim.2015.04.011

128. Chen JJ, Pittock SJ, Flanagan EP, Lennon VA, Bhatti MT. Optic neuritis in the era of biomarkers. Survey Ophthalmol. (2019). doi: 10.1016/j.survophthal.2019.08.001. [Epub ahead of print].

129. Hennes E, Baumann M, Schanda K, Anlar B, Bajer-Kornek B, Blaschek $A$, et al. Prognostic relevance of MOG antibodies in children with an acquired demyelinating syndrome. Neurology. (2017) 89:900-8. doi: 10.1212/WNL.0000000000004312

130. Baumann M, Hennes E, Schanda K, Karenfort M, Korkek B, Seidl $\mathrm{R}$, et al. Children with multiphasic disseminated encephalomyelitis and antibodies to the myelin oligodendrocyte glycoprotein (MOG): extending the spectrum of MOG antibody positive diseases. Mult Scler. (2016) 22:1821. doi: $10.1177 / 1352458516631038$

131. Kitley J, Woodhall M, Waters P, Leite MI, Devenney E, Craig J, et al. Myelin-oligodendrocyte glycoprotein antibodies in adults with a neuromyelitis optica phenotype. Neurology. (2012) 79:1273-7. doi: 10.1212/WNL.0b013e31826aac4e

132. Spadaro M, Gerdes L, Krumbholz M, Ertl-Wagner B, Thaler FS, Schuh E, et al. Autoantibodies to MOG in a distinct subgroup of adult multiple sclerosis. Neurol Neuroimmunol Neuroinflamm. (2016) 3:e257. doi: 10.1212/NXI.0000000000000257

133. Chen J, Flanagan E, Jitprapaikulsan J, Lopez-Chiriboga ASS, Fryer JP, Leavitt JA, et al. Myelin oligodendrocyte glycoprotein antibody-positive optic neuritis: clinical characteristics, radiologic clues, and outcome. Am J Ophthalmol. (2018) 195:8-15. doi: 10.1016/j.ajo.2018.07.020

134. Titulaer M, Hoftberger R, Iizuka T, Leypoldt F, McCracken L, Cellucci T, et al. Overlapping demyelinating syndromes and anti-N-methyl-D-aspartate receptor encephalitis. Ann Neurol. (2014) 75:411-28. doi: 10.1002/ana.24117

135. Chang K, Ro L, Lyu R, Chen CM. Biomarkers for neuromyelitis optica. Clin Chim Acta. (2015) 440:64-71. doi: 10.1016/j.cca.2014.11.004

136. Högel H, Rissanen E, Barro C, Matilainen M, Nylund M, Kuhle J, et al. Serum glial fibrillary acidic protein correlates with multiple sclerosis disease severity. Mult Scler. (2018) 20:1352458518819380. doi: $10.1177 / 1352458518819380$

137. Uzawa A, Mori M, Arai K, Sato Y, Hayakawa S, Masuda S, et al. Cytokine and chemokine profiles in neuromyelitis optica: significance of interleukin-6. Mult Scler. (2010) 16:1443-52. doi: 10.1177/1352458510379247

138. Wang H, Wang K, Zhong X, Dai Y, Qiu W, Wu A, et al. Notable increased cerebrospinal fluid levels of soluble interleukin-6 receptors in neuromyelitis optica. Neuroimmunomodulation. (2012) 19:304-8. doi: 10.1159/000339302

139. Hottenrott $T$, Dersch R, Berger B, Rauer S, Eckenweiler M, Huzly $\mathrm{D}$, et al. The intrathecal, polyspecific antiviral immune response in neurosarcoidosis, acute disseminated encephalomyelitis and autoimmune encephalitis compared to multiple sclerosis in a tertiary hospital cohort. Fluids Barriers CNS. (2015) 12:27. doi: 10.1186/s12987-015-0024-8

140. Carroll W. 2017 McDonald MS diagnostic criteria: evidence-based revisions. Mult Scler. (2018) 24:92-5. doi: 10.1177/1352458517751861

141. Saini M, Khurana D. Chronic relapsing inflammatory optic neuropathy. Ann Indian Acad Neurol. (2010) 13:61-3. doi: 10.4103/0972-2327.61280

142. Miyake H, Inoue A, Tanaka M, Matsuki N. Serum glial fibrillary acidic protein as a specific marker for necrotizing meningoencephalitis in Pug dogs. J Vet Med Sci. (2013) 75:1543-5. doi: 10.1292/jvms.13-0252

143. Fujiwara K, Matsuki N, Shibuya M, Tamahara S, Ono K. Autoantibodies against glial fibrillary acidic protein in canine sera. Vet Rec. (2008) 162:592-3. doi: $10.1136 / v r .162 .18 .592$

144. Tanaka $\mathrm{M}$, Inoue $\mathrm{A}$, Yamamoto $\mathrm{K}$, Tamahara $\mathrm{S}$, Matsuki $\mathrm{N}$. Transglutaminase 2: a novel autoantigen in canine idiopathic central nervous system inflammatory diseases. J Vet Med Sci. (2012) 74:733-7. doi: 10.1292/jvms.11-0507

145. Lamb C, Croson P, Capello R, Cherubini GB. Magnetic resonance imaging findings in 25 dogs with inflammatory cerebrospinal fluid. Vet Radiol Ultrasound. (2005) 37:424-7. doi: 10.1111/j.1740-8261.2005.00003.x 
146. Boudreau C, Dominguez C, Levine J, Mankin J, Anderson KM, Voges AK, et al. Reliability of interpretation of neurologic examination findings for the localization of vestibular dysfunction in dogs. J Am Vet Med Assoc. (2018) 252:830-8. doi: 10.2460/javma.252.7.830

147. Gal R, Vedula S, Beck R. Corticosteroids for treating optic neuritis. Cochrane Database Syst Rev. (2012) 4:CD001430. doi: 10.1002/14651858.CD001430.pub3

148. Shams P, Plant G. Optic neuritis: a review. Int MS J. (2009) 16:82-9.

149. Plant GT. Optic neuritis and multiple sclerosis. Curr Opin Neurol. (2008) 21:16-21. doi: 10.1097/WCO.0b013e3282f419ca

150. Du Y, Li J, Zhang Y, Li K, He JF. Risk factors for idiopathic optic neuritis recurrence. PLoS ONE. (2014) 9:e108580. doi: 10.1371/journal.pone.0108580

151. Garcia M, Ying G, Cocores C, Tanaka JC, Komaromy AM. Evaluation of a behavioral method for objective vision testing and identification of achromatopsia in dogs. Am J Vet Res. (2010) 71:97-102. doi: 10.2460/ajvr.71.1.97

152. Leocani L, Guerrieri S, Comi G. Visual evoked potentials as a biomarker in multiple sclerosis and associated optic neuritis. J Neuroophthalmol. (2018) 38:350-7. doi: 10.1097/WNO.0000000000000704

153. Torres D, Tovar M. Clinical guideline for assessing flash visual evoked potentials in laboratory dogs and normal data for beagle dogs. Scand J Lab Anim Sci. (2016) 42:1-8. doi: 10.23675/sjlas.v42i1.366

154. Kimotsuki T, Yasuda M, Tamahara S, Matsuki N, Ono K. Topographic analysis of flash visual evoked potentials in dogs. J Vet Med Sci. (2005) 67:869-75. doi: 10.1292/jvms.67.869

155. Kimotsuki T, Yasuda M, Tamahara S, Tomihari M, Matsuki N, Ono K. Ageassociated changes of flash visual evoked potentials in dogs. J Vet Med Sci. (2006) 68:79-82. doi: 10.1292/jvms.68.79

156. Bennett J, de Seze J, Lana-Peixoto M, Palace J, Waldman A, Schippling $S$, et al. Neuromyelitis optica and multiple sclerosis: seeing differences through optical coherence tomography. Mult Scler. (2015) 21:678-88. doi: $10.1177 / 1352458514567216$

157. Adhi M, Duker J. Optical coherence tomography-current and future applications. Curr Opin Ophthalmol. (2013) 24:213-21. doi: 10.1097/ICU.0b013e32835f8bf8

158. Hernandez-Merino E, Kecova H, Jacobson S, Hamouche KN, Nzokwe RN, Grozdanic SD. Spectral domain optical coherence tomography (SD-OCT) assessment of the healthy female canine retina and optic nerve. Vet Ophthalmol. (2011) 14:400-5. doi: 10.1111/j.1463-5224.2011. 00887.x

159. Rizzo J, Lessell S. Optic neuritis and ischemic optic neuropathy: overlapping clinical profiles. Arch Ophthalmol. (1992) 109:1668-72. doi: 10.1001/archopht.1991.01080120052024

160. Mari L, Stavinohova R, Dominguez E, Premont J, Oliver J, De Risio L. Ischemic optic neuropathy in a dog with acute bilateral blindness and primary systemic hypertension. J Vet Intern Med. (2018) 32:423-7. doi: $10.1111 /$ jvim. 14878

161. Adesina OO, McNally SJ, Salzman KL, Katz BJ, Warner JEA, McFadden $\mathrm{M}$, et al. Diffusion-weighted imaging and post-contrast enhancement in differentiating optic neuritis and non-arteritic anterior optic neuropathy. Neuroophthalmology. (2017) 42:90-8. doi: 10.1080/01658107.2017.1356856

162. Rizzo J, Andreoli C, Rabinov J. Use of magnetic resonance imaging to differentiate optic neuritis and nonarteritic anterior ischemic optic neuropathy. Ophthalmology. (2002) 109:1679-84. doi: 10.1016/S0161-6420(02)01148-X

163. Coelho A, Cherubini G, De Stefani A, Negrin A, Gutierrez-Quintana R, Bersan E, et al. Serological prevalence of toxoplasmosis and neosporosis in dogs diagnosed with suspected meningoencephalitis in the UK. J Small Anim Pract. (2009) 60:44-50. doi: 10.1111/jsap.12937

164. Hoon-Hanks L, McGrath S, Tyler K, Owen C, Stenglein MD. Metagenomic investigation of idiopathic meningoencephalomyelitis in dogs. J Intern Vet Med. (2018) 32:324-30. doi: 10.1111/jvim.14877

165. Barber R, Li Q, Diniz P, Porter BF, Breitschwerdt EB, Claiborne $\mathrm{MK}$, et al. Evaluation of brain tissue or cerebrospinal fluid with broadly reactive polymerase chain reaction for Ehrlichia, Anaplasma, spotted fever group Rickettsia, Bartonella, and Borrelia species in canine neurological diseases (109 cases). J Vet Intern Med. (2010) 24:372-8. doi: 10.1111/j.1939-1676.2009.0466.x

166. Schatzberg S, Haley N, Barr S, de Lahunta A, Sharp NJ. Polymerase chain reaction screening for DNA viruses in paraffin-embedded brains from dogs with necrotizing meningoencephalitis, necrotizing leukoencephalitis, and granulomatous meningoencephalitis. J Vet Intern Med. (2005) 19:553-9. doi: 10.1111/j.1939-1676.2005.tb02726.x

167. Barber R, Porter B, Li Q, May M, Claiborne MK, Allison AB, et al. Broadly reactive polymerase chain reaction for pathogen detection in canine granulomatous meningoencephalomyelitis and necrotizing meningoencephalitis. J Vet Intern Med. (2012) 26:962-8. doi: 10.1111/j.1939-1676.2012.00954.x

168. Han J, Chang $\mathrm{D}$, $\mathrm{Na}$ K. A multiplex quantitative real-time polymerase chain reaction panel for detecting neurologic pathogens in dogs with meningoencephalitis. J Vet Sci. (2015) 16:341-7. doi: 10.4142 jvs.2015.16.3.341

169. Schwab S, Herden C, Seeliger F, Papaioannou N, Psalla D, Polizopulou Z, et al. Non-suppurative meningoencephalitis of unknown origin in cats and dogs: an immunohistochemical study. J Compar Pathol. (2007) 136:96-110. doi: $10.1016 /$ j.jcpa.2006.11.006

Conflict of Interest: The authors declare that the research was conducted in the absence of any commercial or financial relationships that could be construed as a potential conflict of interest.

Copyright (C) 2019 Posporis, Beltran, Dunning, Espadas, Gillespie, Barry and Wessmann. This is an open-access article distributed under the terms of the Creative Commons Attribution License (CC BY). The use, distribution or reproduction in other forums is permitted, provided the original author(s) and the copyright owner(s) are credited and that the original publication in this journal is cited, in accordance with accepted academic practice. No use, distribution or reproduction is permitted which does not comply with these terms. 